\title{
EXTRACTION AND ATOMIC-ABSORPTION DETERMINATION OF PALLADIUM ON THE BASIS OF THE COMPLEXATION REACTION WITH 2-HYDROXY-5-T-BUTYLPHENOL-4'-METHOXY-AZOBENZENE
}

\section{A.M.Pashajanov}

Institute of Catalysis and Inorganic Chemistrynamed after academicianM.Nagiyev of ANAS,

AZ 1143, H.Javid Ave. 113, Baku, Azerbaijan

aydin.pashajanov@gmail.com

\begin{abstract}
Complexation of Pd (II) with 2-hydroxy-5-T-butylphenol-4'-methoxy-azobenzene (HR) have been researched. The optimum conditions of complex formation and its extraction with chloroform and $n$-butanol, providing the required fullness of binding of palladium ions were found. Stability constant of the cation complex $\mathrm{Pd} \mathrm{R}^{+}\left(\mathrm{IgK}_{\mathrm{st}}=4.3 \cdot 10^{\mathrm{T}}\right)$, and the equilibrium constant of complexation reaction $\left(3.42 \cdot 10^{4}\right)$ were calculated by Komar method. Molar absorption coefficient equals to $(4.3 \pm 0,1) \cdot 10^{4}$. The calibration curve was linear at concentrations of palladium $1 \div 10 \mathrm{mcg} / \mathrm{mL}$.Selective and sensitive technique of extraction-atomic absorption determination of palladium in alloys were developed.
\end{abstract}

\section{Indexing terms/Keywords}

Palladium; complexation; 2-hydroxy-5-T-butylphenol-4'-methoxy-azobenzene; extraction; atomic-absorption determination

\section{Academic Discipline And Sub-Disciplines}

Chemistry

\section{SUBJECT CLASSIFICATION}

Analytical chemistry; Inorganic Chemistry

TYPE (METHOD/APPROACH)

Spectrophotometry, photometry, atomic-absorption

\section{Council for Innovative Research}

Peer Review Research Publishing System

\section{Journal: Journal of Advances in Chemistry}

Vol. 11, No. 9

www.cirjac.com

editorjaconline@gmail.com, editor@cirjac.com 


\section{INTRODUCTION}

Synthesis and study of new organic reagents that reduce the duration of the definition of the elements and increase the accuracy of the analysis is an actual problem of spectrophotometry. In this respect promising reagents for photometric and extraction-atomic absorption determination of palladium ions are nitrogen-containing azocompounds [1-5].

Complexation of palladium ions for analytical purposes in water-organic media is widely discussed in the literature [6-11]. At the same time to increase the sensitivity development of new methods is required for determination of palladium.

Qualitative parameters of complex formation reaction of $\mathrm{Pd}(\mathrm{II})$ with $\mathrm{HR}$, as well as data on the stability of the complex in chloroform is absent in the literature.

To continue their research on finding selective reagents for palladium among nitrogen-containing azo compounds we have studied the complexation reaction of palladium with 2-hydroxy-5-T-butylphenol-4'-methoxy-azobenzene.

This paper studies the extraction concentration conditions of palladium, followed by its atomic absorption determination in complex objects. To increase the sensitivity forpalladium ions for the first time we have applied the method of direct input of the organic extract into the flame.

\section{EXPERIMENTAL}

\section{Reagents and instruments}

Analytically pure reagents were used. For comparison the solution $0.4433 \mathrm{~g}$ of palladium chloride was dissolved in $15 \mathrm{ml}$ of $\mathrm{HCl}$ and made up to $500 \mathrm{ml}$ with distilled water. The concentration of palladium was established gravimetrically [1]. Palladium solutions with low concentrations $\left(1.5 \cdot 10^{-5}\right)$ were prepared by dilutionof stock solution. Reagent solution $\left(3.0 \cdot 10^{-4} \mathrm{M}\right)$ was prepared by dissolving accurately weighed in ethanol.

Reagent,synthesized according to the procedure [12] and purified by recrystallization from ethanol, is an orange crystalline powder. The composition and structure of the reagent were set by elemental analysis, as well as by methods of IR, UV spectroscopy.

To create optimal acidity using $\mathrm{HCl}, \mathrm{H}_{2} \mathrm{SO}_{4}$ and ammonium acetate buffer solution. lonic strength of the solution ( $\mu=0.1$ ) created by adding a calculated amount of $1.0 \mathrm{M} \mathrm{KNO}_{3}$ solution.

The acidity of the solutions was monitored by universal ionomer EF-74. Absorbance of the solution was measured with a spectrophotometer SF-46 and photoelectrocolorimeterKFK-2. Atomic absorption of palladium was measured on the atomic-absorption spectrophotometer AAC-30 from Carl Zeiss JENA.

As light sources we used standard hollow cathode lamps of the same firm. Optimum measurement conditions are listed in Table 1.

Table 1.Conditions of atomic absorption determination of palladium

\begin{tabular}{|c|c|c|c|c|c|}
\hline Elements & $\begin{array}{c}\text { Wavelength, } \\
\mathbf{n m}\end{array}$ & $\begin{array}{c}\text { Lamp current, } \\
\mathbf{m A}\end{array}$ & $\begin{array}{c}\text { Slot, } \\
\mathbf{n m}\end{array}$ & $\begin{array}{c}\text { Acetylene flow, } \\
\mathbf{I} / \mathbf{h}\end{array}$ & $\begin{array}{c}\text { Air flow, } \\
\mathbf{I} / \mathbf{h}\end{array}$ \\
\hline $\mathrm{Pd}$ & 244,8 & 20 & 0,5 & 100 & 500 \\
\hline
\end{tabular}

\section{Technique}

A certain amount of standard solution of palladium, $5 \mathrm{ml}$ of the buffer solution with certain $\mathrm{pH}$ and $0.5 \mathrm{ml}$ of the reagent solution were pouredintoa separatory funnel or stoppered tubes, diluted with the same buffer to $20 \mathrm{ml}$ and the resulting compound was extracted with $10 \mathrm{ml}$ of chloroform or $\mathrm{n}$-butanol. After complete separation of phases extract was sprayed into the air-acetylene flame and atomic absorption of palladium was measured.

\section{RESULTS AND DISCUSSION}

\section{Spectrophotometric study of the reaction}

By interaction of palladium(II) with HR in hydrochloric acid solutions complexes extractable with organic solvents are generated.

Optimal region of $\mathrm{pH}$ of complexation in aqueous solution and its extraction with chloroform is placed in the range of $\mathrm{pH} 2$ 5. The optimal value of $\mathrm{pH}$ of complex formation is 3.5-4. $\mathrm{pH}$ influence on the complexation is shown in Figure 1.

Under optimum conditions the maximum absorption spectrum is observed at $460-500 \mathrm{~nm}$ for the complex and at $350-370$ $\mathrm{nm}$ for reagent. 


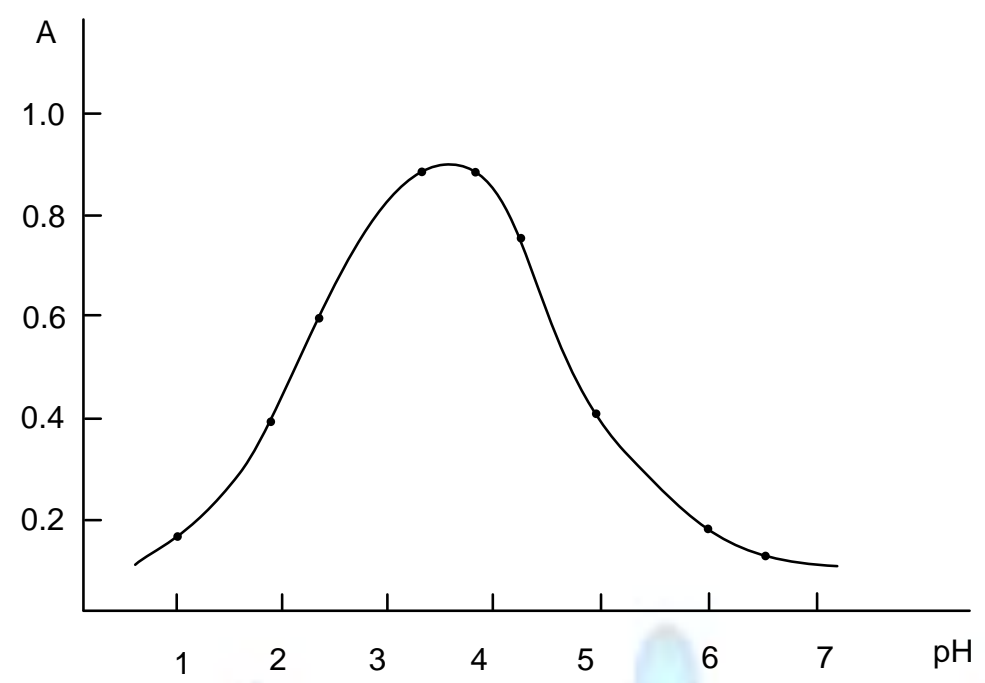

Figure 1.pH influence on the complexation of palladium $\mathrm{Pd}$ (II). $\mathrm{C}_{\mathrm{HR}}=3,9 \cdot 10^{-4} \mathrm{M} ; \mathrm{C}_{\mathrm{Pd}}=1,5 \cdot 10^{-5} \mathrm{M} ; \lambda=500 \mathrm{~nm} ; \mathrm{V}_{\text {org }}=5 \mathrm{ml}$; $\mathrm{I=}, 5 \mathrm{sm}$; background- $\mathrm{H}_{2} \mathrm{O}$; KFK-2.

Thus,complexation is followed by a bathochromic shift on $130 \mathrm{~nm}$ (Figure 2).

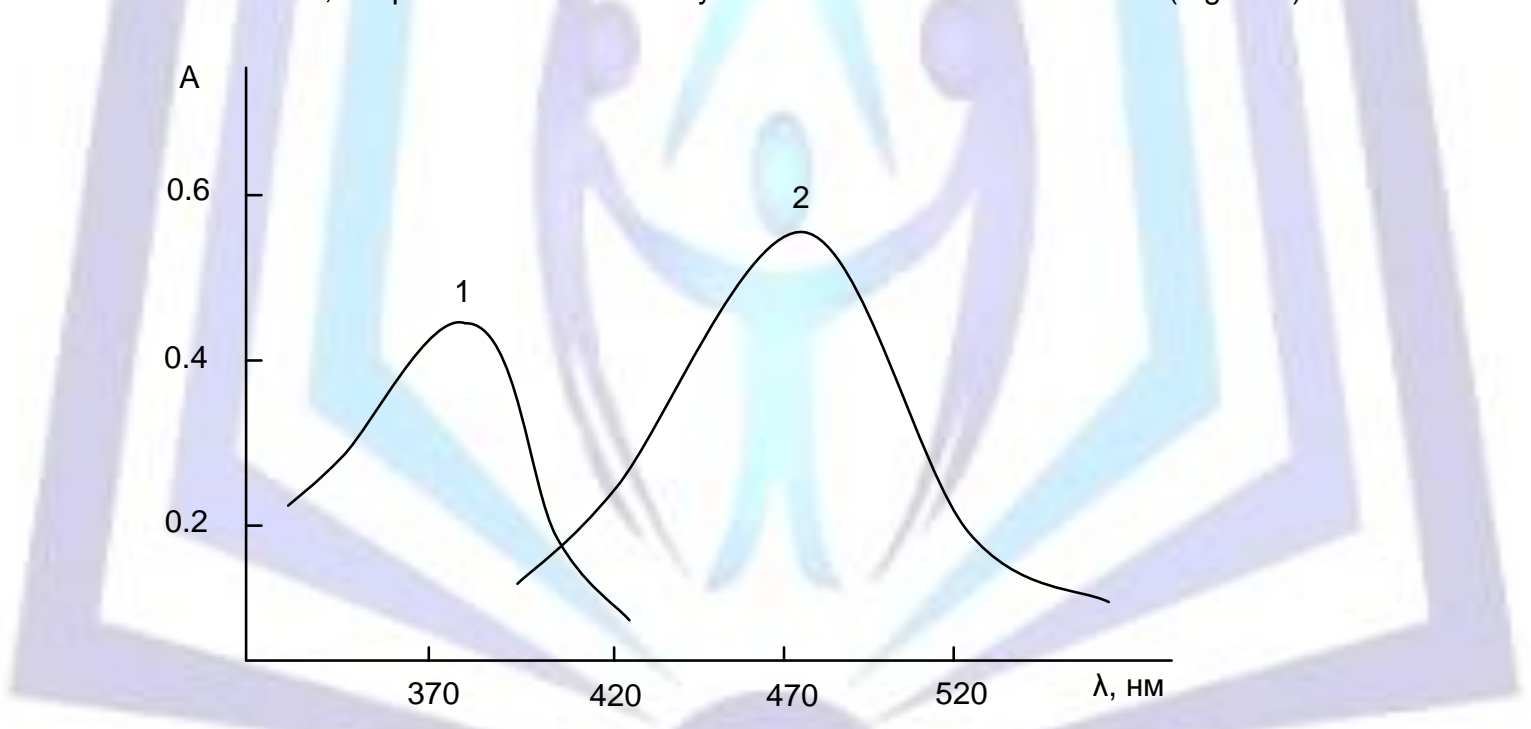

Figure 2. The absorption spectrums of the extracts of reagent (1) and complex of $\mathrm{Pd}(\mathrm{II}) \quad(2) ; \quad \mathrm{C}_{\mathrm{HR}}=3,9 \cdot 10^{-4} \mathrm{M} ; \quad \mathrm{C}_{\mathrm{Pd}}=1,5 \cdot 10^{-5} \mathrm{M} ; \quad \mathrm{V}_{\text {org }}=5 \mathrm{ml}$; $l=0,5 \mathrm{sm} ; \mathrm{KFK}-2$.

By methods of molar ratios and shifting equilibrium[6] it was found thatunder optimal conditions of extraction complex with a ratio of palladium(II) to HR $1: 2$ is formed.

Knowing the ratio of the components in the resulting complex of palladium with HR, and given the state of the system components, reaction of formation and extraction ofuniformly ligand $\mathrm{Pd}(\mathrm{II})$ complex can be written as:

$$
\mathrm{Pd}^{+2}+2 \mathrm{HR} \rightarrow \mathrm{PdR}_{2}+2 \mathrm{H}^{+}
$$

Stability constant of ion associate (IA) in chloroform $\left(4 \cdot 3 \cdot 10^{12}\right)$ and the equilibrium constant of complexation reaction $\left(3.42 \cdot 10^{4}\right.$ at $\mathrm{pH}$ 3.5)are calculated by spectrophotometric data for chloroform and n-butanol solutions of IAusingthe dependence of light absorption of solutions onpH.

Molar absorption coefficient of palladium, calculated by the Tolmachevmethod [6] is (1.8 \pm 0.1$) 10^{4}$. Calibration graph islinear for concentrations of palladium $1-10 \mathrm{mkg} / \mathrm{ml}$. 
The effect of different ions on the results of determination of palladium is shown in Table 2.

Table 2. Effect of diverse ions on the results of the determination of palladium (typed $5 \mathrm{mkg} / \mathrm{ml}$ of palladium)

\begin{tabular}{|c|c|c|c|}
\hline Related ion & Permissible number, $\mathbf{m g}$ & Related ion & Permissible number, mg \\
\hline $\mathrm{Na}(\mathrm{I})$ & 100 & $\mathrm{Fe}(\mathrm{III})$ & 10 \\
\hline $\mathrm{K}(\mathrm{I})$ & 100 & $\mathrm{~V}(\mathrm{~V})$ & 0.5 \\
\hline $\mathrm{Ba}(\mathrm{II})$ & 5 & $\mathrm{~W}(\mathrm{VI})$ & 2.0 \\
\hline $\mathrm{Sr}(\mathrm{II})$ & 5 & $\mathrm{Cl}^{-}$ & 5 \\
\hline $\mathrm{Ca}(\mathrm{II})$ & 5 & $\mathrm{Br}^{-}$ & 5 \\
\hline $\mathrm{Cd}(\mathrm{II})$ & 2 & $\mathrm{I}^{-}$ & 5 \\
\hline $\mathrm{Zn}(\mathrm{II})$ & 2 & $\mathrm{SO}_{4}^{-2}$ & 5 \\
\hline $\mathrm{Cu}(\mathrm{II})$ & 1 & $\mathrm{PO}_{4}^{-3}$ & 10 \\
\hline $\mathrm{Pb}(\mathrm{II})$ & 10 & $\mathrm{NO}_{3}^{-}$ & 10 \\
\hline $\mathrm{Co}(\mathrm{II})$ & 0.5 & $\mathrm{CO}_{3}^{-2}$ & \\
\hline $\mathrm{Ni}(\mathrm{II})$ & 10 & & \\
\hline $\mathrm{Al}(\mathrm{III})$ & 5 & & \\
\hline
\end{tabular}

\section{Extraction ofcomplex}

Extractability of complex was assessed by the distribution coefficient and the degree of extraction. Complex cation with composition $[\mathrm{PdR}]^{+}$formed in aqueous solution in the process of extraction with chloroform moves to interphase boundary in the form of ion associate withcomposition $[\mathrm{PdR}]^{+} \mathrm{An}^{-}$. When using acetate buffer solution fullness of transition of $\mathrm{A}$ to the organic phase is achieved at a single extraction. Such an increase in rapidity and completeness of extraction is probably due to the increase of hydrophobic interactions between organic phase and ion associate. Chloride ions are less hydrophobic than acetate ions and ion associate composition in chloroform can be represented by the formula $[\mathrm{PdR}]^{+}\left[\mathrm{CH}_{3} \mathrm{COO}\right]^{-}$. In single extraction with butanol $95 \%$ of palladium is recovered. Absence of $\mathrm{Pd}^{2+}$ ions in aqueous phase after extraction led to conclude high value of the distribution constant (about $10^{3}$ ). Equilibrium concentrations of $\mathrm{Pd}^{2+}$ content in the aqueous and the organic phase were found by difference. Increase of aqueous phase volume up to 20 $\mathrm{ml}$ did not significantly affect the optical density of the extract in $\mathrm{n}$-butanol. Maximum optical density of the solution is achieved by maintaining of the complex 1-2 min. Complex is stable for two days.

With increasing concentrations of reagent optical densityof the organic phase increases and reaches a plateau at a concentration of $3.2 \cdot 10^{4} \mathrm{M} \mathrm{HR}$.

Almost complete extraction of palladium complex of hydrochloric acid environment is used for the development of methods of extraction-atomic absorption determination of palladium in alloys and ores.Chloroform, dichloroethane, carbon tetrachloride, benzene, toluene, xylene and n-butanol were tested for extraction of complex from organic solvents.Atdirect spraying of extracts into the burnerflame organic solvent must be flammable. Recovery of palladium is maximal by extraction with n-butanol. Atomic absorption of palladium decreases at using of halogenated solvents. More suitable for atomic absorption analysis was n-butanol. It does not change the mode of combustion of the flame, does not create the background in the field of analytical line of palladium and maintains stable combustion, which enables to determine palladium with the direct spraying ofextract into the flame [13].A preliminary extraction separating of palladium and direct introduction ofextracts into the flame can improve the selectivity and sensitivity of the analysis.On the basis of studiesthe methods of extraction-atomic absorption and extraction-photometricdetermination of palladium in complex objects were developed.

A method developed by us for determination of palladium was used for the analysis of standard samples containing palladium (nickel powders, nickel anode and sulfide-copper-nickel ores).

\section{The execution of definition}

Sample of the alloy $(1.0 \mathrm{~g})$ was dissolved under heating in $20 \mathrm{ml}$ of $\mathrm{HNO}_{3}(1: 1)$. Solution was evaporated until the separation of nitrogen oxides. Then $10 \mathrm{ml}$ of the mixtureof concentrated $\mathrm{HNO}_{3}$ and HClratio of $1: 3$ is added and the solution is evaporated to 2-3 ml; this operation is repeated 2-3 times. After cooling, the solution was diluted up to the line with distilled water. Aliquot part of the solution $(10 \mathrm{ml})$ was transferred to theseparatory funnel, acidity of $\mathrm{pH} 3.0-3.5$ is created by adding $\mathrm{HCl}, 1.0 \mathrm{ml}$ ethanol solution of $\mathrm{HR}$ is added, diluted to $25 \mathrm{ml}$ with distilled water and extracted with $10 \mathrm{ml}$ $\mathrm{n}$-butanol $1 \mathrm{~min}$. After phase separation, the extract was sprayed into the air-acetylene flame and the atomic absorption of palladium is measured. In this case the sensitivity of palladium increases 2-3 timescomparing to the use of aqueous solution.Amount of palladium was determined by the calibration graph. 
Accuracy oftechnique is tested by standard model. Results of the determination of palladium in nickel powder, nickel anode and sulfide copper-nickel ores are shown in Table 3, and show the sufficient reliability of the proposed method.

Table 3. Results of the extraction-atomic absorption determination of palladium in nickel powder, nickel anode and sulfide ore. $(n=5 ; p=0.95)$

\begin{tabular}{|l|c|c|c|}
\hline \multicolumn{1}{|c|}{ Object of analysis } & $\begin{array}{c}\text { Certified } \\
\text { content ofPd \% }\end{array}$ & $\begin{array}{c}\text { Received } \\
\text { content of Pd \% }\end{array}$ \\
\hline nickel powder & 0.071 & 0.070 & 0.04 \\
nickel anode & 0.080 & 0.079 & 0.05 \\
sulfide ore & 0.175 & 0.176 & 0.05 \\
\hline
\end{tabular}

Thus, the use of 2-hydroxy-5-T-butylphenol-4'-methoxy-azobenzene as a complexing agent and direct input of the organic phase into the flame allowus to increase the sensitivity ofdetermination of $\mathrm{Pd}^{2+} 2-3$ times.

\section{CONCLUSIONS}

The complex formation of $\mathrm{Pd}(\mathrm{II})$ with 2-hydroxy-5-T-butylphenol-2'-methoxy-azobenzel (HR) and further extraction of complex with chloroform was researched. The optimal conditions provided of the complete of Pd-ions connection of complex formation and its extraction with chloroform were found. By the method of Komar (IgKyct=4.3 $10^{12}$ ). The constant of stability of cation complex was calculated and the constant of equilibrium of complex formation was determined. The extraction-atom-absorbtion method of Pd-ions determination in alloy was worked out.

\section{REFERENCES}

[1] Ginsburg S.I., Yezerskaya N.A., Prokofyeva I.V. and others. Analytical chemistry of platinum metals.M. Nauka. 1972.

[2] Ivanov V.M., Heterocyclic nitrogen containing compounds.M. Nauka. 1982.pp.229.

[3] Yatsimirskiy K.B., Mosin V.V., Kazachkova A.N.Journal of analytical chemistry. 1991.vol.36. pp. 3135.

[4] Price V. (1976). Analytical Atomic-Absorption Spectroscopy. M. Mir. pp. 355.

[5] Popeko I.E., Vasilyev V.V., Timanov A.M., Shaghusultanova G.A.Coordination chemistry. 1991.vol.17.pp.1427.

[6] Rossotti F., RossottiKh..Determiantion of stability constant and other constants of equilibrium in solutions. M. Mir. 1965.

[7] Bulatov M.I., Kalinkin I.P. Practical guidance on photocolorimetric and spectrophotometric analyses.L. Chemistry. 1976.pp. 386.

[8] Popova T.V., Tolmachev V.L., Al-Ansari S.V., Sheglova N.V.Journal of analytical chemistry. 2001.vol.56. №4. pp. 412-416.

[9] Zolotov Y.A., Shkil A.I., Vilenkin V.A., Zdorova E.P., Rukhadze E.G..Journal of analytical chemistry. 1988.vol.XLIII.issue.7.pp. 1266-1272.

[10] Pilirenko A.G., Khvatkova Z.M., Golovina V.B.Journal of analytical chemistry. 1986.vol.XLI.issue.11.pp. 2045-2048.

[11] Endo M., Satake M., Katyal M., Puri B.K.Journal of analytical chemistry.1986.vol.XLI.issue.11.pp. $2041-2044$.

[12] Gasimov V.T., Mejidov A.A.Coordination chemistry.1990.vol.16. №10.pp. 1355.

[13] Gusinskiy M.N., Pashajanov A.M., Nemodruk A.A. Journal of analytical chemistry. 1982. Vol.37. №1.pp.42-48. 